\title{
Traumatic Lateral Listhesis of Lumbar Spine in a Young Female
}

${ }^{1}$ Sanjay Yadav, ${ }^{2}$ Saurabh Singh, ${ }^{3}$ Rohit Amar, ${ }^{4}$ Ramvilas Nag

\begin{abstract}
Traumatic lateral translation is an extremely rare presentation. The diagnosis may be easily missed. An 18-year-old female presented with fall from height and backache and weakness in bilateral lower limbs. On examination, there was tenderness in lumbar spine, step-like deformity; neurological examination revealed no sensory loss and grade III power in both lower limbs without bowel and bladder involvement. Radiographic examination showed anterolateral listhesis of L5 over S1. Magnetic resonance imaging showed spinal canal stenosis and mild compression of traversing caudal roots. Patient was treated with open reduction and stabilization with posterior instrumentation, decompression, and posterolateral fusion. Complete neurological recovery was observed over 1-year follow-up period.
\end{abstract}

Keywords: Lateral, Listhesis, Lumbar, Spine, Traumatic.

How to cite this article: Yadav S, Singh S, Amar R, Nag R. Traumatic Lateral Listhesis of Lumbar Spine in a Young Female. J Postgrad Med Edu Res 2018;52(2):88-89.

\section{Source of support: Nil}

Conflict of interest: None

\section{INTRODUCTION}

Traumatic spondylolisthesis of lumbosacral region is relatively uncommon but lateral translation is an extremely rare presentation and is often present in patients with polytrauma. It is often not thought of and the diagnosis may be easily missed.

\section{CASE REPORT}

An 18-year-old female presented to the emergency room with the history of fall from height of about $4 \mathrm{~m}$ on day 2 of injury with complaints of backache and weakness in bilateral lower limbs. On examination, there was tenderness in lumbar spine, step-like deformity; neurological examination revealed no sensory loss and grade III power in both lower limbs without bowel and bladder involvement. Radiographic examination showed anterolateral

\footnotetext{
${ }^{1}$ Assistant Professor, ${ }^{2}$ Associate Professor, ${ }^{3,4}$ Resident

${ }^{1-4}$ Department of Orthopedics, Banaras Hindu University Varanasi, Uttar Pradesh, India

Corresponding Author: Sanjay Yadav, Assistant Professor Department of Orthopedics, Banaras Hindu University, Varanasi Uttar Pradesh, India, Phone: +919560754591, e-mail: drsanjay. pgi@gmail.com
}

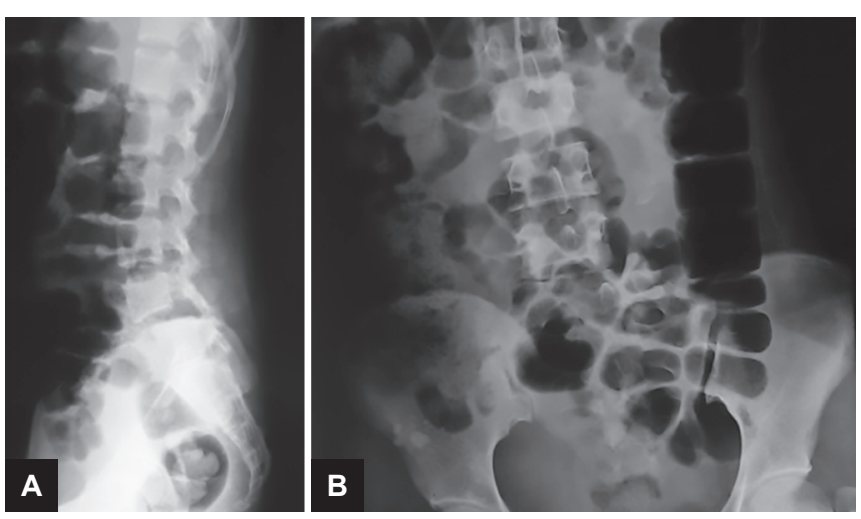

Figs $1 \mathrm{~A}$ and $\mathrm{B}$ : $\mathrm{X}$-rays of lumbosacral spine in anteroposterior and lateral views showing anterolateral listhesis of L5-S1
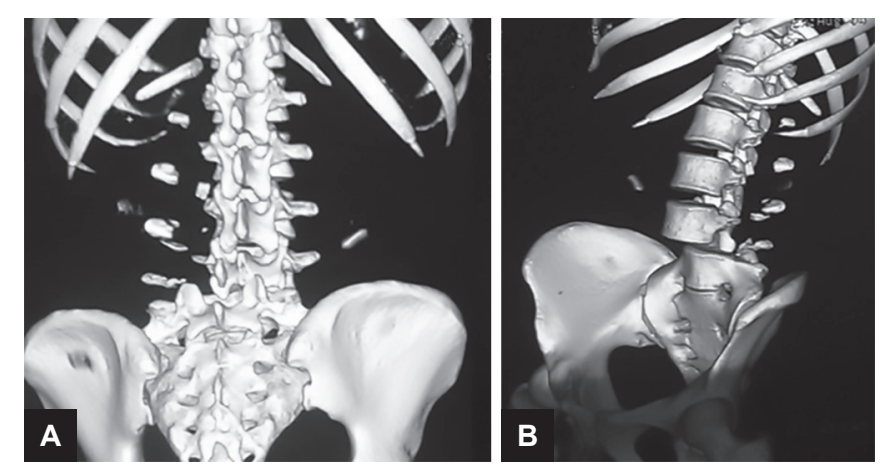

Figs $2 \mathrm{~A}$ and B: Computed tomography scan with three-dimensional reconstruction showing fractures of posterior elements at multiple levels

listhesis of L5 over S1 (Fig. 1). Computed tomography (CT) showed fracture of facet joints of L5-S1 with fracture of posterior elements at multiple levels of lumbar spine (Fig. 2). Magnetic resonance imaging was done to check the cord status and it showed spinal canal stenosis and mild compression of traversing caudal roots (Fig. 3). Patient was treated with open reduction of dislocation and stabilization with posterior instrumentation, decompression, and posterolateral fusion with autologous bone graft (Fig. 4). Six months postoperatively, complete neurological recovery was observed.

\section{DISCUSSION}

Traumatic dislocation of lumbosacral region is often associated with multiple injuries and is a rare presentation and even rarer in females. ${ }^{1}$ There are five types of spondylolisthesis: dysplastic, isthmic, degenerative, traumatic, and pathologic. Traumatic spondylolisthesis is the fracture of posterior elements, rather than the pars 


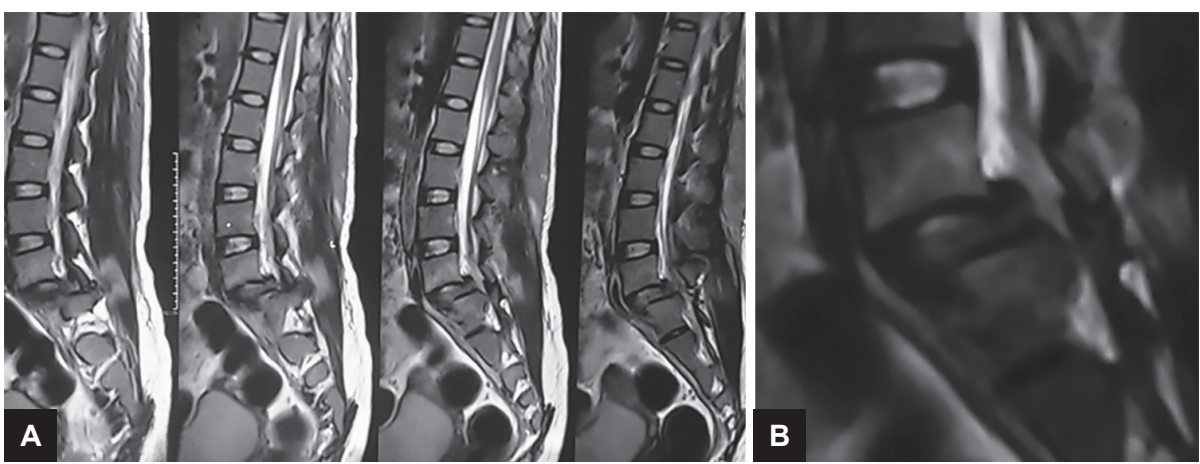

Figs 3A and B: Magnetic resonance imaging showing disk bulge at L5-S1 level with significant canal stenosis

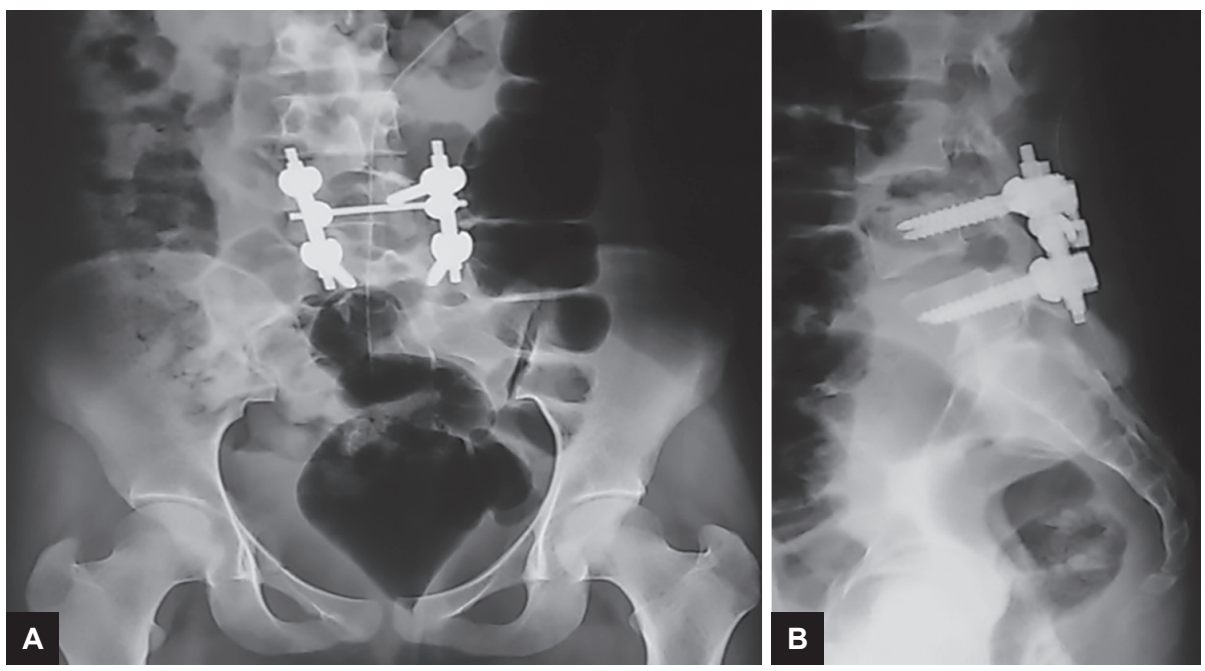

Figs 4A and B: Postoperative $X$-rays showing correction of listhesis with posterior instrumentation

interarticularis, which leads to instability and listhesis. ${ }^{2}$ A combination of hyperflexion and compression are responsible for causing bilateral L5-S1 dislocation but according to Watson-Jones, hyperextension is the main mechanism of the injury. 3,4

In our patient, hyperflexion and compression was the main mechanism of injury. Because of severe osseoligamentous damage, traumatic fracture-dislocation of the lumbosacral spine is considered as highly unstable; being a three-column injury, open reduction and internal fixation is always recommended. ${ }^{5,6}$ Furthermore, early decompression of the cord promotes recovery of neurological function. The timing of decompression and the degree of spinal canal narrowing are the main factors affecting neurological recovery; ${ }^{7}$ our patient was operated on 5th day of injury. Though conservative methods have been described in literature but operative treatment with decompression offers better results and is the most accepted treatment modality. ${ }^{8}$

Traumatic lumbosacral spondylolisthesis is a rare injury pattern. Its diagnosis can be missed initially as it is usually associated with other life-threatening injuries; therefore CT with biplanar reconstructions is mandatory in addition to good-quality conventional radiographs.
Surgical treatment, including reduction, stabilization, and interbody fusion, is the method of choice.

\section{REFERENCES}

1. Vialle R, Charosky S, Rillardon L, Levassor N, Court C. Traumatic dislocation of the lumbosacral junction diagnosis, anatomical classification and surgical strategy. Injury 2007 Feb;38(2):169-181.

2. HuSS, Tribus CB, Diab M, Ghanayem AJ. Spondylolisthesis and spondylolysis. J Bone Joint Surg Am 2008 Mar;90(3):656-671.

3. Tsirikos AI, Saifuddin A, Noordeen MH, Tucker SK. Traumatic lumbosacral dislocation: report of two cases. Spine (Phila Pa 1976) 2004 Apr;29(8):E164-E168.

4. Watson-Jones, R. Fractures and joint injuries. Baltimore (MD): Williams 1940.

5. Aihara T, Takahashi K, Yamagata M, Moriya H. Fracturedislocation of the fifth lumbar vertebra. A new classification. J Bone Joint Surg Br 1998 Sep;80(5):840-845.

6. Davis AA, Carragee EJ. Bilateral facet dislocation at the lumbosacral joint: a report of a case and review of literature. Spine (Phila Pa 1976) 1993 Dec;18(16):2540-2544.

7. Dimar JR 2nd, Glassman SD, Raque GH, Zhang YP, Shields CB. The influence of spinal canal narrowing and timing of decompression on neurologic recovery after spinal cord contusion in a rat model. Spine (Phila Pa 1976) 1999 Aug;24(16):1623-1633.

8. Reinhold M, Knop C, Blauth M. Acute traumatic L5-S1 spondylolisthesis: a case report. Arch Orthop Trauma Surg 2006 Nov;126(9):624-630. 